\title{
JOHN WESTBY: WE NEED TO BE THE FIRST IN CLASS
}

\begin{abstract}
John Wetsby is Associate Vice President of the Global Innovation Center - EMEA at Merck in the Czech Republic. He also chairs the IT Regional Leadership Team for EMEA. His role in the organization is to establish a global IT hub in Prague. In this interview, John Wetsby talks about his project in Prague, shares his opinion on the Central European business environment and cooperation with universities, and describes the main technology trends driving the development of a modern healthcare industry.
\end{abstract}

\begin{abstract}
What are your interests and your passions?
I grew up in Chicago where I spent most of my career as a consultant, and I gradually moved towards the East coast of the U.S. because I met my wife. My interests are especially my three children, then golf, movies and computers. However, I like having a really tight group of family and friends, particularly the children.
\end{abstract}

What would you do if you weren't doing your current profession?

I would definitely teach. I had an education course and I still expect that one day, when I've done my career, I will go teach at a secondary school or a university in the U.S.

\section{Why have you moved to Prague?}

It was quite an interesting challenge to set up an innovation center for a global pharmaceutical company, moving current limits of usage of IT in healthcare. This is a project to create a global IT innovation hub with a significant investment volume of 60 Million USD. I came here on $1^{\text {st }}$ January this year and have started with very little here - actually a very small commercial office. We had no infrastructure; we are building the business from scratch - a start-up. Every month we try to find ways to go faster; we want to hire at least 300 people by the end of next year, for which we will open brand new offices in the center of Prague early next year.
We are part of a 40 billion USD company, which is already very well established, but what we are doing here is completely new for us.

\section{What is actually the main task of your project?}

We're creating a comprehensive set of IT function teams that will serve our entire company and our exterritorial partners as well. And when I say entire IT functions, I mean not only data, not only back office functions. It's a lot of work around helping people develop IT plans and strategies, large programs and projects, and we will recreate our internal platforms such as our analytics platform. If you look at any big IT organization and the scope of what they do, a lot of that we're going to have here. We still have over 2000 IT colleagues worldwide, but 400-500 people will be here in Prague.

\section{Why did you choose Prague?}

We actually wanted to be in Europe. Since for a global company with a lot of headquarters in America and Asia, Central Europe is where we wanted to be. Considering our global hub, we'll be part of the network, and we have nothing like it in Europe anywhere. By choosing Europe, we will have access to twelve different markets. We had over 15 different criteria. We calculated in detail the balance of what we will want, and eventually Prague seemed the best. It was primarily the talents we would have access to. In my opinion, if you look at 


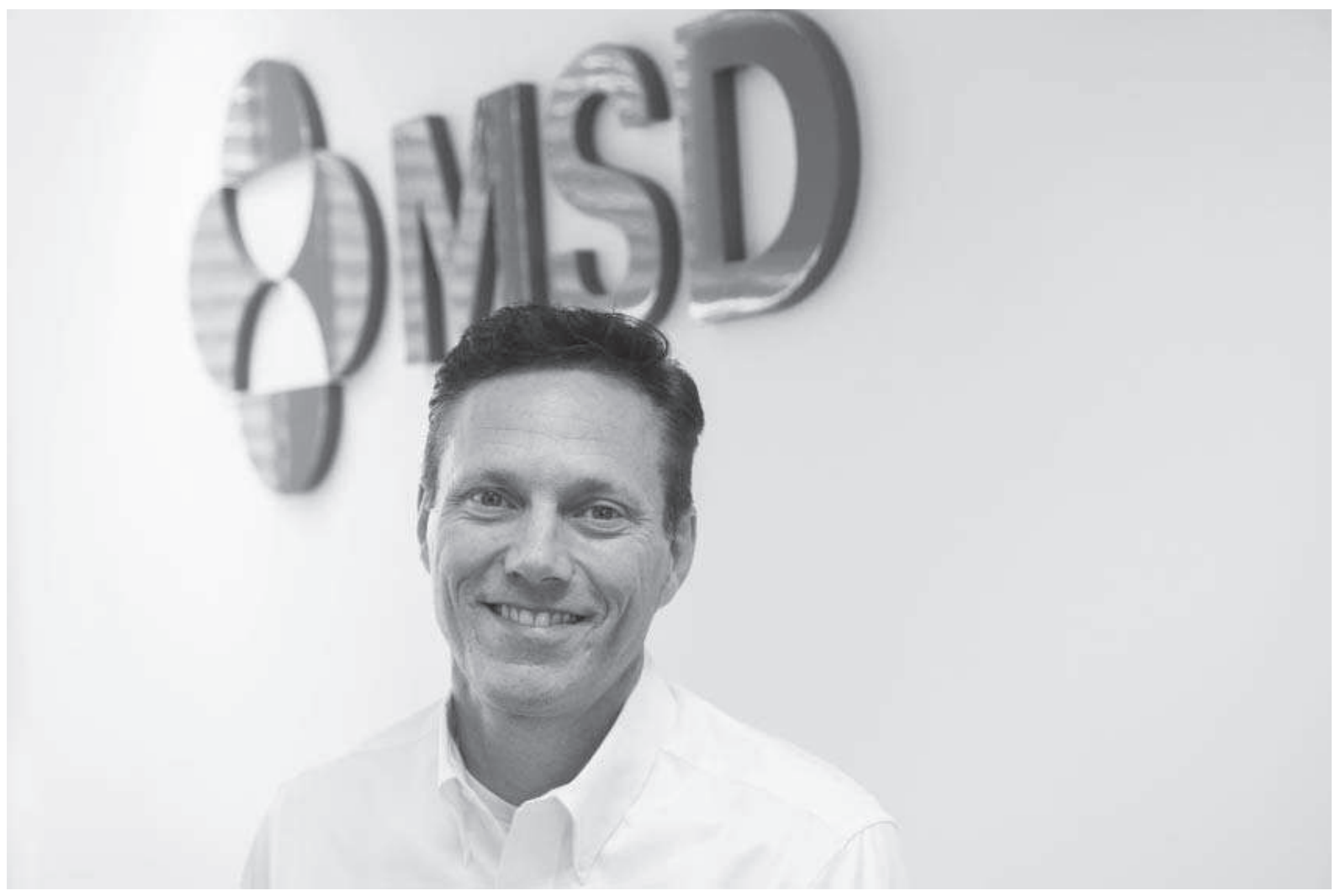

Photo: Jan Branč

other cities in Central Europe, Prague is the best in this sense. It's perfectly geographically located between the U.S. and South East Asia, it's easier to do business here than in some other Western European markets, and it's also a matter of costs. All of these things will balance. The university system is improving, so it's not only the talents who are already here, what we see growing is universities - we have, for example, a partnership with VŠE (University of Economics, Prague). English proficiency is also valuable for the company - everybody has to speak English well because of the people we are working with. And if we put all these things together, Prague makes the most sense for us.

\section{And how do you proceed? Is it more difficult than expected; is it different?}

We didn't expect to be able to grow so quickly. That's a very pleasant surprise. We've found really wonderful people here. One of the biggest surprises is how interested they are in our message around healthcare. Your system of healthcare is good quality, government provided, and people are mostly happy with it. Moreover, the IT workforce we're targeting is very interested in healthcare. We've been able to grow quickly, so we are achieving our plans to be fully operational here.

\section{How many nationalities do you have here?}

It's at least fifteen nationalities; some $25 \%$ of our workforce is non-Czech and non-Slovak. We want to be a global firm where English is the primary language.

\section{How do you work with them?}

We are still learning. We just started in January. We reinforce the international aspect of their jobs. It's OK when they speak Czech in their small teams but they all will be working with international colleagues. And we also kind of celebrate diversity so when we do the orientation, I go around the room and I always highlight to them that many of them are not Czech or Slovak. So far it seems to be working; the question is whether we can maintain it. To your question, I don't have any difficulties with blending people together. I am sure it will create some because of difficult cultures and styles, but we are finding it rather positive now. 


\section{What are the differences between these nationalities?}

We are simply trying to find people who want to come here and learn new things and do things differently. We are not screening for specific cultures for specific jobs. We don't have too many from Western markets here, we have a couple of Italians and some people from Ireland, but we just want people whose energy is very high.

\section{What are the specifics of Central European people?}

Based on my ten months working experience with Czech people, I would like to stress their strong desire to work on something meaningful. They like challenges and they don't want to be bored; they want to learn new things. There are parts of the world where people lose their energy to do something new, and it's not the question of age, it's the whole workforce.

\section{What is, according to you, the development and future of Central Europe?}

Truly, I think Central European markets are positioned to build functions like ours that are more global and international. They are going to have to develop managers, particularly managers who can work in a multinational environment. I think there is so much global interest in Central and Eastern Europe right now. That presents a great opportunity. But then, the challenge is to grow a generation of leaders who can work more in global than local.

\section{What is your personal managerial approach to people here? How do you work with them?}

In general, it's good to tell them: you are going to work in a network, so you have to focus on building relationships, in particular with colleagues outside of Prague. That's a challenge for people everywhere. When we build our teams and we communicate, we highlight the transparency, teaching people the open way to communicate, not to control information but to share it, and then to realize that to get the work done, they need to influence their peers particularly. On one hand, there is direct management in which you have to be very efficient, but there is also leadership which is around influencing your peers. And then also career management. We are building a strong employee base where we plan to give people the opportunity to develop their careers. We want to give people the opportunity to grow, respecting the fact that some people can prefer to do the same thing for ten years.

\section{What about the systems which could facilitate that?}

We are investing a lot into what is called collaboration technologies to really reinforce the sharing and opening up of discussion threads. We'll certainly invest in systems around learning and development training, but that already exists. You will see that our scenario here will be at the front of trying to improve how to collaborate in technology systems. We have these things installed right now, but they need to be improved.

\section{What are the main technology trends today?}

The first thing is the explosion of data, including what is known as "big data". So we have to have the technologies that are much more agile and scale much better to a lot of people who bring really diverse data together like never before. It's not just that the data is there; increasingly, we need the data to prove the value of what we do to the whole healthcare community. The second thing is the consumerization of IT; the fact that at some point in the future, the vast majority of people will be in some way managing their own healthcare. And that presents opportunities but also challenges. We are not allowed to develop relationships directly with a lot of the patients since in most markets we have government restrictions in that regard. How to keep people healthier including the use of our products is a big challenge for us.

\section{So, coming back to one of the first questions, this is actually what you are doing here.}

It's not the only thing, but all that we are doing here is about providing data to our business to be able to make rapid and more informed decisions and to better show the efficiency from the economic standpoint, not just the medical one. There will be more and more data that is of interest for us. More data is coming from consumers and patients. Everything that we will do here will be about getting the right information to the right people and it's so much more complex now. It doesn't mean that we already don't have such systems, but the industry has completely changed over the last 10-20 years.

\section{Some say that only $4 \%$ of all data is useful, the rest is useless. Do you agree with that?}

Yes. Four percent of something small is easy to deal with, but $4 \%$ of almost infinity is so much harder. If you look at the data which cross our entire business spectrum, every area has become more and more complex: data around customers because of the social media development; data around science is more complex; manufacturing gets also more and more complex. And you have to deal 
with all these data to maintain the level of quality and to make quick decisions.

\section{Imagine that it's the year 2064. What will have changed in the meantime, mainly in the pharma industry?}

I hope that healthcare will be somehow automatic and available to everybody, even to the people living in rain forests, because of technology. I don't think that the role of the pharma industry will become more complex, but it will change and pharma companies will likely have evolved into broader healthcare companies. There will certainly be companies like ours which develop market products, provide services and even the solutions, including IT solutions.

\section{You mentioned innovation which is currently a buzz word. What do you understand by innovation?}

We believe that for success we need to be the first in class. We are producing really advanced pharmaceutical products and for them we need to have really complex information. There is a unique manufacturing technology and certainly you need the lab technology that's required, but from the information perspective, it's much more about the complexity of data. We want to be innovative in terms of how to do more with less. We want to provide platforms that allow, in a much more effective way to the rest of our organization and even people outside of MSD, to innovate on top of these platforms. In my opinion, innovation is not having something completely new. That's a part of it. Innovation is taking what we have and redefining how we provide it so that people everywhere can innovate on top of it. And we can't centralize innovation. So we don't want to centralize innovation here. We are trying to make this center provide such a great set of assets for everybody else to innovate that we can just sit and smile.

\section{The final topic I would like to open is cooperation with universities. You said that perhaps one day you will become a teacher. How do you perceive the cooperation with universities and what do you expect to get from it?}

I have a number of people in my team who come from companies where the focus on universities and fresh graduates is very high. And when you develop them, you give them a lot of training and coaching, and then you focus on just really assessing the students, you will find energetic people who have good communication skills. We have a common belief that we want to have a good number of university graduates here. That means we need to keep good relationships with universities. You can't just come to a job fair once a year and expect that this will make people have a strong interest in your company. In my days of consultancy, you had entire teams that focused on different university campuses. They had programs where they invested in the relationships with the faculties, they did projects with students. I think that the bonds we develop will help increase the number of people who are interested in working for us. And as long as it's beneficial to the universities, the system is win-win. So that's our general perspective on it and it's translated in our specific partnerships like our partnership with VŠE (University of Economics, Prague), ČVUT (Czech Technical University in Prague) and we are going to develop it with Charles University. They are learning what the really good projects to do are, what are good investments to make, what are technology centers, etc. I want to get to the point where it's just standard practice how we do the projects and collaborate on things but it takes time to develop that. I want to get to the point where it's so well understood that when you leave one school here and go to the next even though some people have left, it still keeps going. That will probably take a couple of years to do. And of course, I also want our company to not be seen as a traditional pharmaceutical company as much as an innovation based company. One thing I worry about is the image of MSD because most Czechs either don't know MSD or they specifically know that it's a pharmaceutical company that sells products.

\section{Do you have experience from other regions concer- ning the cooperation with academia?}

I'm bringing my experience from the US. We have some European offices that have participated in recruiting but we're not trying to base or model here on a particular region. The universities are very different in Europe and in the US.

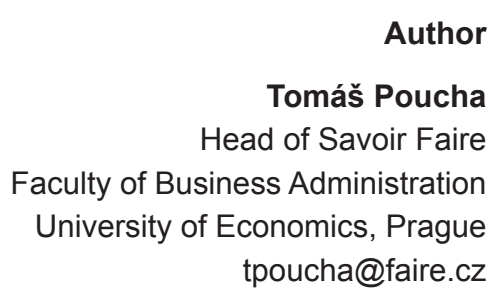

